\title{
PENGARUH PENGGUNAAN ABU VULKANIK SEBAGAI BAHAN PENGISI (FILLER) CAMPURAN AC - WC TERHADAP KARAKTERISTIK MARSHALL
}

\author{
Nurmaidah ${ }^{1}$ \\ ${ }^{1}$ Dosen Fakultas Teknik Sipil, Universitas Medan Area \\ (nurmaidahmidah@gmail.com)
}

\begin{abstract}
ABSTRAK
Karakteristik abu vulkanik ini relatif berbeda dengan debu tanah kering yang biasa dijumpai pada musim kemarau. Abu vulkanik terbentuk dari pembekuan magma yang dierupsikan secara eksplosif. Maka dari itu abu vulkanik bisa menjadi bahan pengisi (filler) dalam campuran aspal ACWC. Maksud dari penelitian ini adalah untuk menganalisa pengaruh pemanfaatan abu vulkanik sebagai bahan pengisi (filler) terhadap nilai uji marshall campuran AC-WC. Pada campuran AC-WC yang biasanya menggunakan filler semen portland, pada penulisan ini filler semen portland akan dibandingkan dengan menggunakan filler abu vulkanik terhadap alat uji marshall dalam campuran AC-WC dengan menggunakan berat jenis agregat yang sama. Penelitian ini menggunakan metode eksperimental yang dilakukan di laboratorium dengan variasi kadar aspal rencana 5,0\%; 5,5\%; 6,0\%; $6,5 \% ; 7,0 \%$. Sampel yang digunakan berjumlah masing-masing 3 buah pada setiap variasi kadar aspal rencana. Sebelum pembuatan benda uji material agregat dan material aspal harus diuji terlebih dahulu dan pengujian benda uji menggunakan alat uji marshall test. Untuk pembuatan benda uji dapat dilihat dari tabel hasil gradasi agregat gabungan. Tujuan dari pengujian dengan menggunakan alat uji marshall test adalah untuk mencari nilai stability, berat jenis bulk, dan kadar aspal optimumnya. Dari hasil penelitian perbandingan Marshall sisa dari kadar aspal optimum yang berbeda dapat disimpulkan untuk penggunaan semen portland sebagai filler dalam campuran ac-wc lebih baik nilai stabilitasnya dibandingkan dengan abu vulkanik sebagai filler dalam campuran ac-wc $1105 \mathrm{~kg}$ berbanding dengan $1095 \mathrm{~kg}$.
\end{abstract}

Kata Kunci : Abu vulkanik, Aspalt concreate - wearing course, Filler, Karakteristik Marshall, Semen Portland

\begin{abstract}
Characteristic of this volcanic ash have relative different with dust dry ground that can be meet in dry season. Volcanic ash formed to the magma eruption in explosive. therefore volcanic ash can be filler in mixture asphalt $a c-w c$. The purpose of the research is analyze effect volcanic ash to the filler to mark marshall ac-wc. In The acwo mix which usually use portland cement filler, at this writing portland cement filler will be compared using volcanic ash filler to marshall test equipment in ac-wc mix by using the weight of the kind of aggregate. The research use experimental method that use in this laboratory by asphalt variation plan $5,0 \% ; 5,5 \% ; 6,0 \% ; 6,5 \%$; $7,0 \%$. Samples used were each 3 pieces on each variation of asphalt content plan. Before the making of the specimen material aggregate and asphalt material should be tested and the test specimen using test equipment marshall test. For producing test specimens can be seen from the table the results of the combined aggregate gradation. The purpose of the test using test equipment marshall test is to find the value of stability, the weight of kind of density, and the optimum asphalt content. The results comparative studies of marshall the rest of the optimum asphalt content that is different can be concluded for the user of portland cement as filler in a mixture of ac-wc better value stability compared than volcanic ash as filler in a mixture of ac-wc $1105 \mathrm{~kg}$ compared to $1095 \mathrm{~kg}$.
\end{abstract}

Keywords: Aspalt concreate - wearing course, Filler,Portland Cement, Marshall Characteristic, Volkanic Ash 


\section{Pendahuluan}

Aspal beton sebagai bahan untuk konstruksi jalan sudah lama dikenal dan digunakan secara luas dalam pembuatan jalan. Aspal beton atau asphaltic concrete adalah campuran dari agregat bergradasi menerus dengan bahan bitumen. Kekuatan utama aspal beton ada pada keadaan butir agregat yang saling mengunci dan sedikit filler sebagai mortar.

Filler merupakan salah satu bahan yang berfungsi sebagai pengisi rongga-rongga dari suatu campuran beraspal, disamping itu filler berfungsi pula sebagai media untuk pelumasan aspal terhadap permukaan agregat.

Pada tanggal 24 Mei 2015 terjadi erupsi Gunung Sinabung, yang mengeluarkan material vulkanik yang berukururan abu ke seluruh penjuru lereng Sinabung. Abu vulkanik terbentuk dari pembekuan magma yang dierupsikan secara eksplosif. Sebagian butiran dari abu ini mempunyai bentuk runcing, dan karena kandungan silikanya yang besar, abu ini mempunyai sifat absorbs yang tinggi.

Material vulkanik yang keluar dari dalam perut bumi karena meletusnya Gunung Merapi terdiri dari batuan yang berukuran besar hingga berukuran halus, yang berukuran besar biasanya jatuh disekitar kawah dalam radius $5-7 \mathrm{~km}$, sedangkan yang berukuran halus sampai ratusan bahkan ribuan $\mathrm{km}$ dari kawah disebabkan oleh adanya hembusan angin

Tujuan dari penelitian ini adalah untuk mengetahui pengaruh pemanfaatan abu vulkanik sebagai filler terhadap nilai uji marshall campuran ac-wc terutama nilai stabilitasnya. dan membandingkan hasil uji marshall campuran ac-wc dengan menggunakan filler semen portland dan abu vulkanik.

\section{Kajian Teori}

\subsection{Klasifikasi Agregat}

Berdasarkan ukuran butiran agregat dapat diklasifikasikan menjadi tiga kelompok yaitu :

\section{a. Agregat Kasar}

Agregat kasar adalah butiran yang tertahan saringan No.4 (4,75 mm). Fungsi agregat kasar dalam campuran aspal beton adalah :

1) Memberikan stabilitas campuran dari kondisi saling mengunci dari masing masing agregat kasar dan tertahan suatu aksi perpindahan

2) Stabilitas ditentukan oleh bentuk dan tekstur permukaan agregat kasar (kubus dan kasar)

\section{b. Agregat Halus}

Agregat halus adalah butiran yang lolos saringan No.4 (4,75 mm) dan tertahan No.200 (0,075 mm). Fungsi agregat halus dalam campuran aspal beton adalah:

1) Menambah stabilitas dari campuran dengan memperkokoh sifat saling mengunci dari agregat kasar dan untuk mengurangi rongga udara agregat kasar.

2) Semakin besar tekstur permukaan agregat halus akan menambah stabilitas campuran dan menambah kekasaran permukaan perkerasan jalan.

3. Agregat halus pada saringan No.8 sampai dengan saringan No.30 penting dalam memberikan kekasaran yang baik untuk kendaraan.

4. Pada gap graded, agregat halus saringan No.8 sampai dengan saringan No.30 dikurangi agar diperoleh rongga udara yang memadai untuk jumlah aspal tertentu sehingga permukaan gap graded cenderung halus.

5. Agregat halus pada saringan No.30 sampai dengan No.200 penting untuk menaikan kadar aspal, sehingga akan bertambah awet.

6. Keseimbangan proporsi penggunaan agregat kasar dan halus penting agar diperoleh permukaan yang tidak licin dengan jumlah kadar aspal yang diinginkan.

c. Filler

Filler adalah bahan berbutir halus yang mempunyai fungsi sebagai pengisi pada pembuatan campuran aspal. Filler didefinisikan sebagai fraksi debu mineral lolos saringan no. $200 \quad(0,074 \mathrm{~mm})$ bisa berupa semen atau abu, dan harus dalam keadaan kering (kadar air maksimal 1 \%).

\subsection{Pengujian Agregat}

Agregat yang akan dipergunakan sebagai material campuran perkerasan jalan 


\section{Pengaruh Penggunaan Abu Vulkanik Sebagai bahan Pengisi (Filler) Campuran AC- WC Terhadap karakteristik Marshall}

harus memenuhi persyaratan sifat dan gradasi agregat seperti yang telah ditetapkan dalam spesifikasi pekerjaan jalan. Maka agregat yang akan digunakan harus di uji terlebih dahulu :

1) Analisa Saringan Agregat Halus dan Agregat Kasar

2) Berat Jenis dan Penyerapan Agregat Kasar

3) Berat Jenis dan Penyerapan Agregat Halus

4) Berat Isi Agregat

5) Kelekatan Agregat terhadap Aspal

6) Keausan Agregat dengan Mesin Los Angeles

\subsection{Aspal Concrete - Wearing Course (AC- WC)}

Beton aspal adalah jenis perkerasan jalan yang terdiri dari campuran agregat dan aspal, dengan atau tanpa bahan tambahan. Materialmaterial pembentuk beton aspal dicampur di instalasi pencampur pada suhu tertentu, kemudian diangkut ke lokasi, dihamparkan dan dipadatkan. Suhu pencampuran ditentukan berdasarkan jenis aspal yang akan digunakan. Jika semen aspal, maka pencampuran umumnya antara $145-155^{\circ} \mathrm{C}$, sehingga disebut beton aspal campuran panas. Campuran ini dikenal dengan hotmix.

Gradasi agregat gabungan untuk campuran AC-WC yang mempunyai gradasi menerus tersebut ditunjukkan dalam persen berat agregat, harus memenuhi batas-batas dan harus berada di luar daerah larangan (restriction zone) yang diberikan dalam Tabel 2.5. di bawah ini dengan membandingkan dengan AC-BC yang mempunyai ukuran butir agregat maksimum $25 \mathrm{~mm}$ atau 1 " dan ACBase $37,5 \mathrm{~mm}$ atau $1 \frac{1}{1 / 2}$. Sedangkan AC-WC mempunyai ukuran butir agregat maksimum $19 \mathrm{~mm}$ atau $3 / 4^{\prime \prime}$.

Tabel 1. Gradasi Agregat Untuk Campuran Lapis Beton

\begin{tabular}{|c|c|c|c|}
\hline \multirow{2}{*}{$\begin{array}{l}\text { Ukuran } \\
\text { Ayakan } \\
(\mathbf{m m})\end{array}$} & \multicolumn{3}{|c|}{ Laston (AC) } \\
\cline { 2 - 4 } & WC & BC & Base \\
\hline 37,5 & - & - & 100 \\
\hline 25 & - & 100 & $90-100$ \\
\hline 19 & 100 & $90-100$ & $76-90$ \\
\hline 12,5 & $90-100$ & $75-90$ & $60-78$ \\
\hline 9,5 & $77-90$ & $66-82$ & $52-71$ \\
\hline 4,75 & $53-69$ & $46-64$ & $35-54$ \\
\hline 2,36 & $21-40$. & $30-49$ & $23-41$ \\
\hline
\end{tabular}

\begin{tabular}{|c|c|c|c|}
\hline \multirow{2}{*}{$\begin{array}{l}\text { Ukuran } \\
\text { Ayakan } \\
(\mathbf{m m})\end{array}$} & \multicolumn{3}{|c|}{ Laston (AC) } \\
\cline { 2 - 4 } & WC & BC & Base \\
\hline 1,18 & $21-40$ & $18-38$ & $13-30$ \\
\hline 0,600 & $14-30$ & $12-28$ & $10-22$ \\
\hline 0,300 & $9-22$ & $7-20$ & $6-15$ \\
\hline 0,150 & $6-15$ & $5-13$ & $4-10$ \\
\hline 0,075 & $4-9$ & $4-8$ & $3-7$ \\
\hline
\end{tabular}

Sumber : Spesifikasi Umum Bina Marga 2010, Revisi 3, Divisi 6

Di bawah ini merupakan ketentuan sifatsifat campuran beraspal panas di Indonesia yang dikeluarkan oleh Bina Marga. Hal tersebut merupakan acuan dalam penelitian ini.

Tabel 2. Ketentuan Sifat-sifat Campuran

\begin{tabular}{|c|c|c|c|c|}
\hline \multirow{2}{*}{ Sifat - sifat Campuran } & & \multicolumn{3}{|c|}{ Laston } \\
\hline & & Lapis & Lapis & Pondasi \\
\hline \multicolumn{2}{|l|}{ Jumlah tumbukan per bidang } & & 75 & 112 \\
\hline \multirow{2}{*}{$\begin{array}{l}\text { Rasio partikel lolos ayakan } 0,075 \mathrm{~mm} \\
\text { dezgan kadar aspal efektif }\end{array}$} & Mn. & & 1,0 & \\
\hline & Maks. & & 1,4 & \\
\hline \multirow{2}{*}{ Rengga dalam campuran (\%) (2) } & Mn. & & 3,0 & \\
\hline & Maks. & & 5,0 & \\
\hline Rcngza dalam Agregat (VMA) (\%) & Mn. & 15 & 14 & 13 \\
\hline Rongga Terisi Aspal (\%) & Mn. & 65 & 65 & 65 \\
\hline Stabilitas Marshall (kg) & Mn. & & 800 & $1800^{(1)}$ \\
\hline \multirow{2}{*}{ Pelelehan (mm) } & Mn. & & 2 & 3 \\
\hline & Maks. & & 4 & $6^{(1)}$ \\
\hline $\begin{array}{l}\text { Stabilitas Marshall Sisa (\%) setelah } \\
\text { perendaman selama } 24 \text { jam, } 60^{\circ} \mathrm{C}\end{array}$ & Mn. & & 90 & \\
\hline $\begin{array}{l}\text { Rcngga dalam campuran (\%) pada } \\
\text { Kepadatar membal (refusal) }\end{array}$ & Mn. & & 2 & \\
\hline
\end{tabular}

Sumber : Spesifikasi Umum Bina Marga 2010, Revisi 3, Divisi 6

\section{Metodologi Penelitian}

Penelitian ini dilakukan di laboratorium

PT. Karya Murni Perkasa dengan dasar menggunakan sistem pencampuran aspal panas Asphalt Concrete - Wearing Course (ACWC) menurut Spesifikasi Umum Bina Marga 2010, Revisi 3, Divisi 6.

\section{1 Prosedur Perencanaan Penelitian}

Untuk menentukan kadar aspal optimum diperkirakan dengan penentuan Garis Pemotong antara VIM Marshall dengan VIM PRD. Ditentukan 2 (dua) kadar aspal di atas dan 2 (dua) kadar aspal dengan kadar filler yang sama. Sebelum menentukan kadar aspal optimum harus dibuat terlebih dahulu benda uji dengan variasi kadar aspal rencan yaitu $5,0 \% ; \quad 5,5 \% ; 6,0 \% ; \quad 6,5 \% ; \quad 7,0 \%$. Kemudian 
dilakukan penyiapan benda uji untuk tes Marshall sesuai tahapan berikut ini :

a. Tahap I

Berdasarkan variasi kadar aspal rencana $5,0 \% ; 5,5 \% ; 6,0 \% ; 6,5 \% ; 7,0 \%$ benda uji dibuat dengan komposisi filler yang sama antara abu vulkanik dan semen portland $1,9 \%$, untuk menentukan komposisi agregat terlebih dahulu agregat harus digradasi untuk mencari SPGR setiap agaregat agar dapat menetukan komposisi masing-masing agregat. Setelah diketahui komposisi agregat barulah bisa dibuat benda ujinya dengan masing-masing tiga benda uji pada setiap kadar aspal rencana. Kemudian dilakukan pengujian Marshall standar dengan 2x75 tumbukan dan pengujian durabilitas untuk menentukan VIM, VMA, VFA, kepadatan, stabilitas, kelelehan, dan hasil bagi Marshall(MQ).

b. Tahap II

Perincian perkiraan jumlah sampel yang akan digunakan dalam pengujian dapat dilihat pada jumlah sampel penelitian seperti Tabel 2. di bawah ini :

Tabel 3. Jumlah Sampel Yang Direncanakan

\begin{tabular}{|c|c|c|c|c|c|c|}
\hline \multirow{2}{*}{\multicolumn{2}{|c|}{ Variasi Kadar Aspal Rencana }} & $5,0 \%$ & $5,5 \%$ & $6,0 \%$ & $6,5 \%$ & $7,0 \%$ \\
\hline & & \multicolumn{5}{|c|}{ Benda Uji } \\
\hline \multirow{2}{*}{$\begin{array}{l}\text { Marshall Test } 2 \times 75 \\
\text { tumbukan }\end{array}$} & Abu Vulkanik & 3 & 3 & 3 & 3 & 3 \\
\hline & Semen Portland & 3 & 3 & 3 & 3 & 3 \\
\hline \multirow{2}{*}{$\begin{array}{l}\text { Kepadatan Mutlak } \\
\text { (PRD) 2x400 } \\
\text { tumbukan }\end{array}$} & Abu Vulkanik & & 2 & 2 & 2 & \\
\hline & Semen Portland & & 2 & 2 & 2 & \\
\hline \multicolumn{2}{|c|}{ Jumlah } & \multicolumn{5}{|c|}{42} \\
\hline & \multicolumn{2}{|c|}{$\begin{array}{c}\text { Lama Rendaman } \\
30 \text { menit }\end{array}$} & \multicolumn{2}{|c|}{$\begin{array}{c}\text { Lama Rendaman } \\
24 \text { jam }\end{array}$} & \\
\hline & & \multicolumn{4}{|c|}{ Benda Uji } & \\
\hline \multirow{2}{*}{$\begin{array}{l}\text { Kadar Aspal } \\
\text { Optimum }\end{array}$} & Abu Vulkanik & \multicolumn{2}{|c|}{2} & \multicolumn{2}{|c|}{2} & \\
\hline & Semen Portland & \multicolumn{2}{|c|}{2} & \multicolumn{2}{|c|}{2} & \\
\hline \multicolumn{2}{|c|}{ Jumlah } & \multicolumn{4}{|c|}{8} & \\
\hline \multicolumn{2}{|c|}{ Jumlah Total } & \multicolumn{4}{|c|}{$\begin{array}{c}42+8=50 \text { Benda } \\
\text { Uji }\end{array}$} & \\
\hline
\end{tabular}

\subsection{Pengujian Material Agregat}

Dalam pemilihan bahan agregat diupayakan menjamin tingkat penyerapan air yang paling rendah. Hal itu merupakan antisipasi atas hilangnya material aspal yang terserap oleh agregat. Agregat dapat terdiri atas beberapa fraksi, misalnya fraksi kasar, fraksi
Untuk mencari kadar aspal optimum terlebih dahulu harus mencari nilai VIM dari kepadatan mutlak 2x400 tumbukan. Karena untuk mencari kadar aspal optimum dengan cara memotong garis VIM Marshall dengan nilai maksimal 5 dan memotong garis VIM PRD dengan nilai minimum 2, setelah didapat nilai dari garis yang memotong VIM Marshal dan VIM PRD nilainya ditambhakan lalu dibagi 2 dan itulah nilai kadar aspal optimumnya.

c. Tahap III

Setelah didapat nilai kadar aspal optimum dilanjut dengan mencari nilai Marshall Sisa atau keawetan umur aspal dengan pengujian lama rendaman, yang pertama lama rendaman 30 menit dan yang kedua lama rendaman 24 jam dengan nilai kadar aspal optimum yang telah didapat. Kemudian ditest dengan alat uji marshall untuk menentukan VIM, VMA, VFA, stabilitas, kelelehan, dan hasil bagi Marshall (MQ) dari kadar aspal optimum. 


\section{Pengaruh Penggunaan Abu Vulkanik Sebagai bahan Pengisi (Filler) Campuran AC- WC Terhadap karakteristik Marshall}

\subsection{Pengujian Material Aspal}

Penggunaan aspal Pen 60 disesuaikan dengan kondisi suhu udara rata-rata $25^{\circ} \mathrm{C}$. Metode pengujian aspal sesuai Spesifikasi Umum Bina Marga 2010 dengan mengacu pada SNI 06-6399-2000.

Tabel 4. Ketentuan Aspal

\begin{tabular}{|c|c|c|c|}
\hline No & Karakteristik & $\begin{array}{c}\text { Metode } \\
\text { Pengujian }\end{array}$ & $\begin{array}{c}\text { Persyara } \\
\text { tan }\end{array}$ \\
\hline 1 & $\begin{array}{c}\text { Penetrasi, } 25^{\circ} \mathrm{C} \\
(0,1 \mathrm{~mm}) \\
\end{array}$ & $\begin{array}{l}\text { SNI } 06- \\
2456-1991 \\
\end{array}$ & $60-70$ \\
\hline 2 & $\begin{array}{c}\text { Viskositas } \\
\text { Dinamis } 60^{\circ} \mathrm{C} \\
\text { (Pa.s) }\end{array}$ & $\begin{array}{l}\text { SNI } 06- \\
6441-2000\end{array}$ & $160-240$ \\
\hline 3 & $\begin{array}{c}\text { Viskositas } \\
\text { Kinematis } 135^{\circ} \mathrm{C} \\
60^{\circ} \mathrm{C}(\mathrm{cSt})\end{array}$ & $\begin{array}{l}\text { SNI } 06 \text { - } \\
6441-2000\end{array}$ & $\geq 300$ \\
\hline 4 & $\begin{array}{c}\text { Titik Lembek } \\
\left({ }^{\circ} \mathrm{C}\right)\end{array}$ & $\begin{array}{l}\text { SNI } \\
2434: 2011\end{array}$ & $\geq 48$ \\
\hline 5 & $\begin{array}{c}\text { Daktilitas pada } \\
25^{\circ} \mathrm{C}(\mathrm{c})\end{array}$ & $\begin{array}{l}\text { SNI } \\
2434: 2011\end{array}$ & $\geq 100$ \\
\hline 6 & Titik Nyala $\left({ }^{\circ} \mathrm{C}\right)$ & $\begin{array}{l}\text { SNI } \\
2434: 2011\end{array}$ & $\geq 232$ \\
\hline 7 & $\begin{array}{c}\text { Kelarutan } \\
\text { dalam } \\
\text { Tricloroethylene } \\
(\%) \\
\end{array}$ & $\begin{array}{l}\text { AASHTO } \\
\text { T44-03 }\end{array}$ & $\geq 99$ \\
\hline 8 & Berat Jenis & $\begin{array}{l}\text { SNI } \\
2434: 2011\end{array}$ & $\geq 1,0$ \\
\hline
\end{tabular}

\section{Analisis Data dan Pembahasan}

\subsection{Hasil Pemeriksaan Filler Abu Vulkanik}

Berdasarkan hasil penelitian tindakan.Data hasil Pemeriksaan filler abu vulkanik merupakan data hasil laboratorium. Hasil pengujian abu vulkanik telah memenuhi syarat sebagai filler. Hasil pemeriksaan dapat dilihat pada Tabel berikut

Tabel 5. Hasil Pemeriksaan Filler Abu Vulkanik

\begin{tabular}{|c|c|c|c|c|c|}
\hline \multirow{2}{*}{$\begin{array}{l}\text { Pem } \\
\text { erik } \\
\text { saan }\end{array}$} & \multirow{2}{*}{$\begin{array}{c}\text { No. } \\
\text { Saringa } \\
\mathbf{n}\end{array}$} & \multirow{2}{*}{$\begin{array}{c}\text { Berat } \\
\text { Tertaha } \\
\text { n (gram) }\end{array}$} & \multicolumn{3}{|c|}{ Komulatif Tertahan } \\
\hline & & & $\begin{array}{c}\text { Berat } \\
\text { (gram) }\end{array}$ & $\%$ & $\begin{array}{c}\% \\
\text { Lolos }\end{array}$ \\
\hline \multirow{3}{*}{ I } & 100 & 15,3 & 15,3 & 5,1 & 94,9 \\
\hline & 200 & 34,1 & 49,4 & 16,47 & 85,53 \\
\hline & Pan & 250,6 & 300 & 100 & 0 \\
\hline \multicolumn{6}{|c|}{ Jumlah } \\
\hline \multirow{3}{*}{ II } & 100 & 14,9 & 14,9 & 4,97 & 95,03 \\
\hline & 200 & 35,4 & 35,3 & 16,77 & 82,23 \\
\hline & Pan & 249,7 & 249,7 & 100 & 0 \\
\hline \multicolumn{6}{|c|}{ Jumlah } \\
\hline
\end{tabular}

\subsection{Hasil Gradasi Agregat Gabungan}

Kualitas agregat dapat diketahui dengan cara pemeriksaan percobaan sehingga diperoleh data laboratorium. Sebelum pembuatan benda uji, dilakukan pembuatan rancang campur (mix design). Perencanaan rancang campur meliputi perencanaan gradasi agregat, penentuan aspal dan pengukuran komposisi masing - masing fraksi baik agregat, aspal dan filler abu vulkanik dan semen portland. Gradasi yang digunakan mengacu pada Spesifikasi Umum Bina Marga 2010 Revisi 3 Divisi 6.

\section{Tabel 6. Ketentuan Aspal}

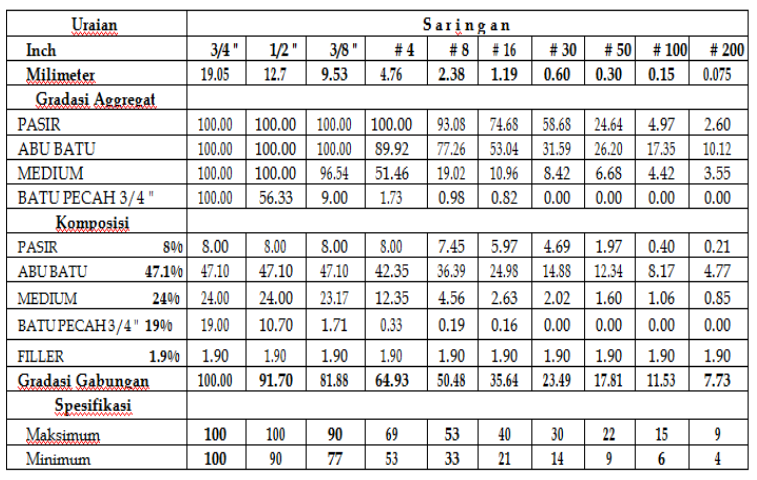

Sumber : Data Lapangan Laboratorium PT. Karya Murni

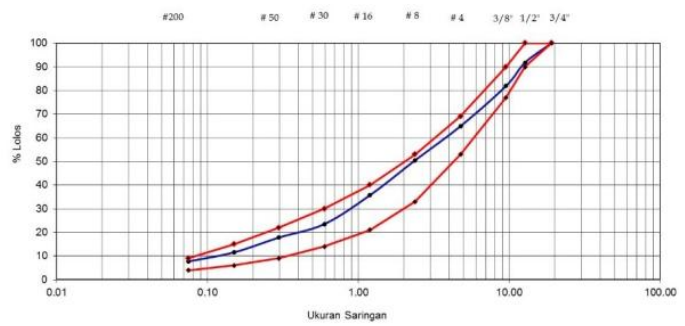

Gambar 1. Grafik Gradasi Agregat Gabungan

\subsection{Hasil Pemeriksaan Aspal}

Data hasil pemeriksaan aspal penetrasi $60 / 70$ merupakan data hasil pengujian laboratorium. Dari hasil pengujian yang telah dilakukan, aspal mempunyai karakteristik yang telah memenuhi spesifikasi Petunjuk Lapis Aspal Beton sesuai Spesifikasi Umum Bina Marga 2010 Revisi 3 Divisi 6. Hasil pemeriksaan aspal seperti yang terlihat pada Tabel berikut ini : 
Tabel 8. Hasil Pemeriksaan Aspal

\begin{tabular}{|c|c|c|c|c|}
\hline \multirow[b]{2}{*}{ No } & \multirow{2}{*}{$\begin{array}{c}\text { Jenis } \\
\text { Pemeriks } \\
\text { aan }\end{array}$} & \multicolumn{2}{|c|}{ Syarat } & \multirow[t]{2}{*}{ Hasil } \\
\hline & & Min & Maks & \\
\hline 1 & $\begin{array}{c}\text { Penetrasi, } \\
25^{\circ} \mathrm{C}(0,1 \\
\mathrm{mm})\end{array}$ & 60 & 79 & 70,1 \\
\hline 2 & $\begin{array}{c}\text { Titik } \\
\text { Lembek } \\
\left({ }^{\circ} \mathrm{C}\right)\end{array}$ & 48 & 58 & $48,33^{\circ} \mathrm{C}$ \\
\hline 3 & $\begin{array}{c}\text { Titik Nyala } \\
\left({ }^{0} \mathrm{C}\right)\end{array}$ & 200 & - & $350^{\circ} \mathrm{C}$ \\
\hline 4 & $\begin{array}{c}\text { Titik Bakar } \\
\left({ }^{\circ} \mathrm{C}\right)\end{array}$ & 200 & - & $370^{\circ} \mathrm{C}$ \\
\hline 5 & $\begin{array}{c}\text { Daktilitas, } \\
25^{\circ} \mathrm{C}(5 \mathrm{~cm} \\
\mathrm{mnt})\end{array}$ & 100 & - & $>150 \mathrm{~cm}$ \\
\hline 6 & $\begin{array}{c}\text { Berat Jenis } \\
(\mathrm{gr} / \mathrm{cc})\end{array}$ & 1 & - & $\begin{array}{l}1,02 \\
\mathrm{gr} / \mathrm{cc}\end{array}$ \\
\hline
\end{tabular}

Tabel 9. Hasil Pengujian Marshall Pada Kadar Aspal Rencana dengan 2x75 Tumbukan

\begin{tabular}{|c|c|c|c|c|c|c|}
\hline \multirow{3}{*}{ Sifat Marshal } & \multirow{2}{*}{ Kadar Filler } & \multicolumn{5}{|c|}{ Kadar Aspal } \\
\hline & & 5.0 & 5.5 & 6.0 & 6.5 & 7.0 \\
\hline & $100 \%$ Abu Wulkanik & 2.232 & 2.256 & 2.271 & 2.277 & 2.257 \\
\hline Berat Jenis Bulk (gr/cc) & $100 \%$ Semen Portland & 2.229 & 2.253 & 2.278 & 2.287 & 2.266 \\
\hline \multirow{3}{*}{ Rongga Dalam Agregat (VMA) (\%) } & 100\% Abu Vulkanik & 16.92 & 16.48 & 16.35 & 16.57 & 17.74 \\
\hline & $100 \%$ Semen Portland & 17,03 & 16.59 & 16.11 & 16.22 & 17.43 \\
\hline & $\frac{\text { Minimum }}{100 \% \text { Abu Vulkanik }}$ & 7.05 & 540 & 4.08 & 316 & $333>2>3$ \\
\hline \multirow{2}{*}{$\begin{array}{l}\text { Rongga Dalam Campuran (VIM) } \\
(\%)\end{array}$} & $100 \%$ Semen Portland & 7.18 & 5.53 & 3.81 & 2.75 & 2.96 \\
\hline & Minimum & & & $\frac{3.0}{50}$ & & \\
\hline \multirow{2}{*}{ Rongga Terisi Aspal (VFB) (\%) } & $\begin{array}{l}100 \% \text { Abu Vulkanik } \\
100 \% \text { Semen Portland }\end{array}$ & $\frac{58.30}{57.86}$ & $\frac{67.23}{66.68}$ & $\frac{75.02}{76.35}$ & 80.94 & $\begin{array}{l}81.20 \\
82.99\end{array}$ \\
\hline & Minimum & & & & & \\
\hline \multirow{2}{*}{ Stability (kg) } & $100 \%$ Abu Vulkanik & 850 & $\frac{999}{957}$ & 1077 & $\frac{1145}{1180}$ & 1082 \\
\hline & $\begin{array}{l}\text { 100\% Semen Portland } \\
\text { Minimum }\end{array}$ & & & 800 & & \\
\hline \multirow{3}{*}{ Kelelehan (Flow) (mm) } & $100 \%$ Abu Vulkanik & 2.52 & $\frac{2.7}{2.7}$ & 3.42 & 3.77 & \\
\hline & $100 \%$ Semen Portland & 2.40 & 2.70 & 3.35 & 3.77 & 3.47 \\
\hline & $\begin{array}{l}\text { Manimum } \\
\text { Maksimum } \\
\end{array}$ & & & 4 & & \\
\hline \multirow{2}{*}{ Marshall Ouotient (MO) (kg/mm) } & $100 \%$ Abu Vulkanik & 338 & 363 & 315 & 304 & 312 \\
\hline & $100 \%$ Semen Portland & 315 & 35 & 326 & 313 & 309 \\
\hline
\end{tabular}

Sumber : Data Lapangan Laboratorium PT. Karya Murni

\subsection{Mencari Kadar Aspal Optimum}

Untuk mencari kadar aspal optimumnya menggunakan perhitungan rata-rata yaitu :

\{(VIM Marshall + VIM PRD) / 2\}. Untuk kadar aspal optimum dengan filler abu vulkanik maka didapat $(5,6+6,5) / 2=\mathbf{6 . 0 5 \%}$. Sedangkan untuk kadar aspal optimum dengan filler semen portland $(5,56+6,5) / 2=\mathbf{6 . 0 3} \%$.

\subsection{Perbandingan Hasil Rata-rata Pengujian} Dengan Menggunakan Filler Abu Vulkanik dan Semen Portland

Perbandingan hasil pengujian benda uji dapat dilihat pada gambar 2 sampai dengan gambar 9 di bawah ini

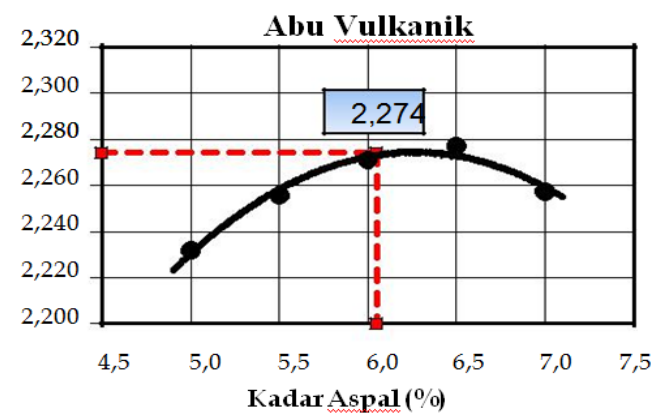

Gambar 2. Berat Jenis Abu Vulkanik KAO $6,05 \%$

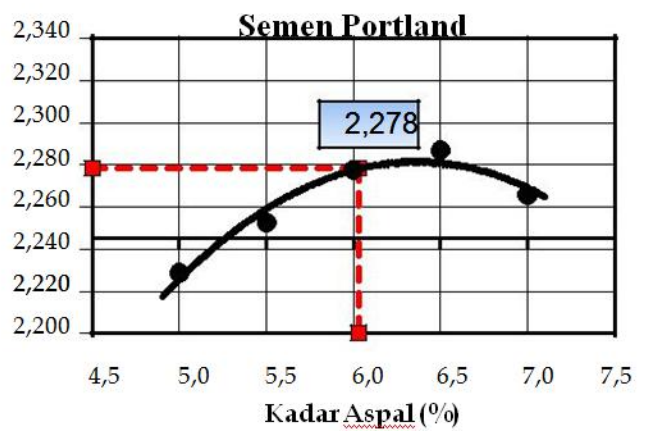

Gambar 3. Berat Jenis Abu Vulkanik KAO $6,03 \%$

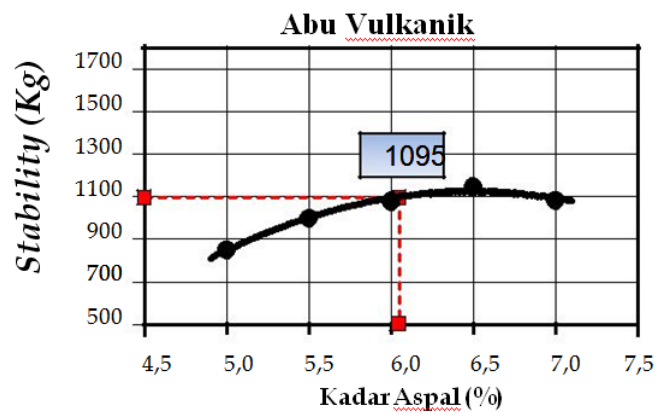

Gambar 4. Berat Jenis Abu Vulkanik KAO $6,05 \%$

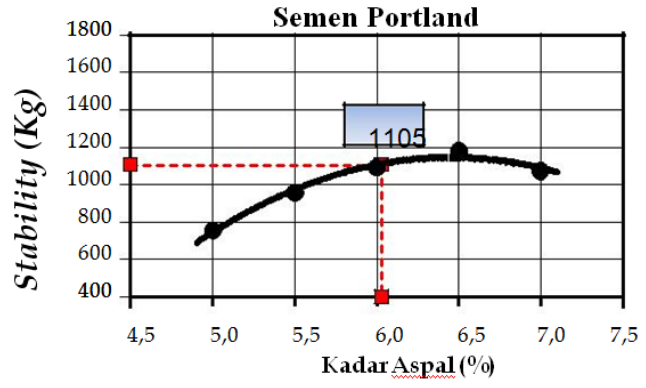

Gambar 5. Stabilitas Semen Portland KAO $6,03 \%$ 


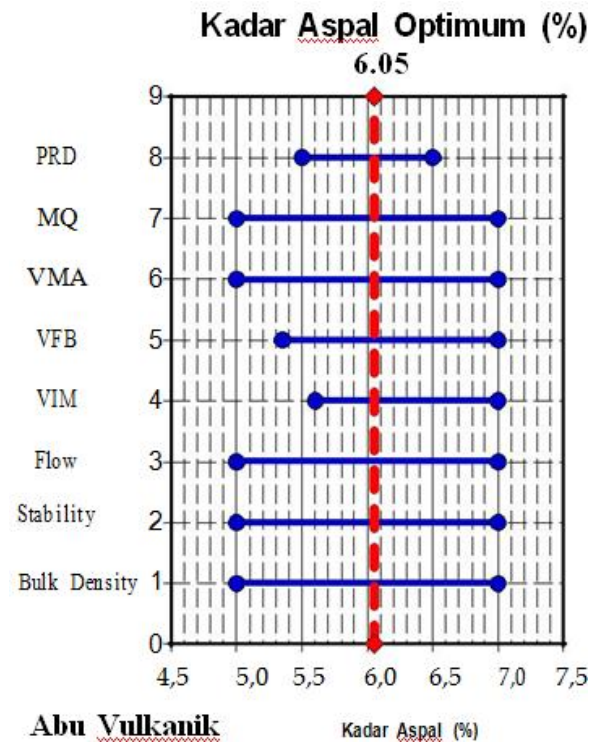

Gambar 6. Kadar Aspal Optimum Abu Vulkanik

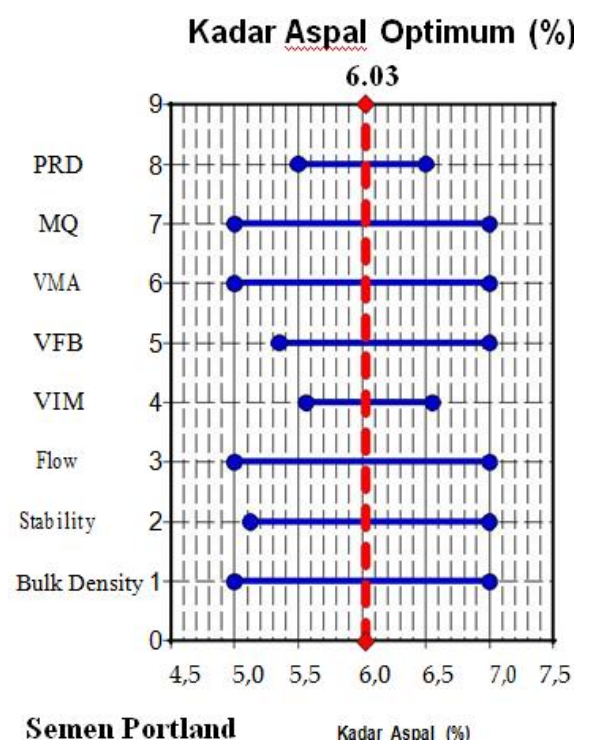

Gambar 7. Kadar Aspal Optimum Semen Portland

Perbandingan hasil nilai angka pada kedua percobaan benda uji dapat dilihat pada Tabel berikut ini.

\begin{tabular}{|l|c|c|}
\hline Sifat Marshall & $\begin{array}{c}\text { Filler } \\
\text { Abu } \\
\text { Vulkanik }\end{array}$ & $\begin{array}{c}\text { Filler } \\
\text { Semen } \\
\text { Portland }\end{array}$ \\
\hline $\begin{array}{l}\text { Bulk Density } \\
\text { (gr/cc) }\end{array}$ & 2.274 & 2.278 \\
\hline Stability (kg) & 1095 & 1105 \\
\hline Flow (mm) & 3.4 & 3.37 \\
\hline VIM (\%) & 3.95 & 3.80 \\
\hline VFB (\%) & 75.50 & 76.40 \\
\hline VMA (\%) & 16.32 & 16.15 \\
\hline MQ (kg/mm) & 326 & 330 \\
\hline PRD (\%) & 2.75 & 2.89 \\
\hline Asphalt (\%) & 6.05 & 6.03 \\
\hline
\end{tabular}

Dari kedua percobaan ini hasil uji marshall dengan lama perendaman dan kadar aspal optimum dapat diketahui nilai stability dan berat jenis yang paling tinggi adalah dengan menggunakan filler semen portland dengan nilai 2,278 gr/cc dan $1105 \mathrm{~kg}$.

\subsection{Kesimpulan}

Dari hasil penelitian benda uji perbandingan antara filler abu vulkanik dengan filler semen portland dalam campuran Asphalt Concrete - Wearing Course (ac - wc) terhadap karakteristik marshall maka dapat diambil kesimpulan sebagai berikut :

a) Pada uji Marshall dengan kadar aspal rencana seluruh sifat - sifat Marshall yang didapatkan mempunyai hasil yang hampir sama untuk masing - masing campuran dengan dua macam jenis filler abu Hasil untuk kadar aspal rencana pada berat jenis dan stabilitas dapat disimpulkan semakin tinggi kadar aspalnya maka semakin tinggi nilai stabilitasnya. Untuk filler abu vulkanik terhadap pengaruh campuran acwc memenuhi persyaratan dalam standard Spesifikasi Umum Bina Marga 2010 Revisi 3 yaitu $1095 \mathrm{~kg}$ dengan batas minimum 
untuk nilai stabilitas $800 \mathrm{~kg}$.

b) Hasil untuk kadar aspal rencana pada berat jenis dan stabilitas dapat disimpulkan semakin tinggi kadar aspalnya maka semakin tinggi nilai stabilitasnya. Untuk filler abu vulkanik terhadap pengaruh campuran ac-wc memenuhi persyaratan dalam standard Spesifikasi Umum Bina Marga 2010 Revisi 3 yaitu $1095 \mathrm{~kg}$ dengan batas minimum untuk nilai stabilitas $800 \mathrm{~kg}$.

c) Untuk perbandingan Marshall sisa dari kadar aspal optimum yang berbeda dengan test marshall dapat disimpulkan bahwa penggunaan semen portland sebagai filler dalam campuran ac-wc menghasilkan nilai stabilitas dan berat jenis yang lebih baik dibandingkan dengan abu vulkanik dengan nilai stabilitas 1180 $\mathrm{kg} \geq 1095 \mathrm{~kg}$.

\section{Daftar Pustaka}

Anas Tahir, Jurnal SMARTek, Vol. 7, No. 4, Nopember 2009: $256 \quad$ - 278, Karakteristik Campuran Beton Aspal (Ac-Wc) Dengan Menggunakan Variasi Kadar Filler Abu Terbang Batu Bara.

Badan Standardisai Nasional BSN, ICS 91.100.10, SNI15-2049-2004,Semen Portland.

Departemen Pekerjaan Umum Direktorat Jenderal Bina Marga, Pemanfaatan Asbuton Buku 3 Campuran Beraspal Panas dengan Asbuton Olahan, No: 001 - 03 / BM / 2006.

Departemen Pekerjaan Umum Direktorat Jendral Bina Marga 2009, Spesifikasi Khusus Seksi 5.7 Lapis Pondasi Pasir Aspal.

Hadi Ali, Jurnal Rekayasa Vol. 15 No. 1, April 2011 Karakteristik Campuran Asphalt Concrete-Wearing Course (AcWc) Dengan Penggunaan Abu Vulkanik Dan Abu Batu Sebagai Filler.

Mochamad Shamier, Evaluasi Karakteristik Campuran Laston Ac - Wc, 2008.

Proyek Jalan Teori \& Praktek, Arthur Wignall Edisi Keempat, 2003.

Rian Putrowijoyo, Kajian Laboratorium Sifat Marshall Dan Durabilitas Asphalt Concrete-Wearing Course (AcWc) Dengan Membandingkan Penggunaan Antara Semen Portland dan Abu Batu Sebagai Filler, 2006. 